\title{
Corticosteroid resistance in chronic asthma
}

\author{
J CARMICHAEL, I C PATERSON, P DIAZ, G K CROMPTON, A B KAY, I W B GRANT
}

\begin{abstract}
Fifty-eight patients with chronic asthma in whom airflow obstruction was relieved by bronchodilator aerosols but not by oral corticosteroids were compared with 58 other chronic asthmatics who responded equally well to both treatments. The two groups were matched for age and sex. The only significant clinical differences between the two groups were that in the "corticosteroidresistant" patients there was a more frequent family history of asthma and a longer duration of symptoms. Resistant patients also had a relatively lower peak expiratory flow rate in the morning than later in the day and a greater degree of bronchial reactivity to methacholine. Such features, however, may not be specific criteria of corticosteroid resistance since they were also observed in untreated asthmatics who subsequently responded well to corticosteroids. The failure of prednisolone to inhibit a monocyte-mediated bronchial reaction may explain why some chronic asthmatics do not respond to corticosteroids.

Patients with corticosteroid-resistant asthma should be recognised at an early stage so that regular treatment with oral corticosteroids may be withdrawn. Failure to do this results in needless exposure to the risk of developing serious side effects.
\end{abstract}

Respiratory Unit, Northern General Hospital, and Departments of Medicine (Western General Hospital) and Respiratory Medicine, University of Edinburgh

J CARMICHAEL, MB, MRCP, medical registrar

I C PATERSON, MB, MRCP, senior medical registrar

G K CROMPTON, MB, FRCP, consultant physician and senior lecturer

I W B GRANT, MB, FRCP, consultant physician and senior lecturer

Department of Pathology, University of Edinburgh

A B KAY, FRCP, DSC, senior lecturer (present appointment: professor of clinical immunology, Cardiothoracic Institute, Brompton Hospital, London)

P DIAZ, MD, PHD, research fellow

\section{Introduction}

All physicians with experience of chronic asthma will have seen patients who are resistant to systemic treatment with corticosteroids, even when given in very large doses. There is no doubt that these patients are asthmatic, since a pronounced reduction in airflow obstruction occurs after inhaling a bronchodilator aerosol. Nevertheless, because they are resistant to oral and inhaled corticosteroids-and usually to all other drugs, including cromoglycate and xanthine derivatives-their chronic symptoms can seldom be adequately controlled. The asthma in such patients is usually severe: they are seriously disabled for long periods and at any time may develop acute episodes for which hospital treatment is urgently required. Though such patients are relatively few, they account for a high proportion of the total attendances at most respiratory outpatient clinics.

There must be some reason why airflow obstruction is rapidly and completely relieved by a short course of oral prednisolone in some patients with chronic asthma, while in others corticosteroids administered in high dosage, either by mouth or by intravenous infusion, have little or no effect. We have therefore tried to identify any factors which could influence the response to corticosteroids of patients with chronic asthma.

\section{Patients}

Fifty-eight patients with chronic asthma who were considered to be "corticosteroid resistant" were compared with 58 patients deemed to be "corticosteroid responsive"-that is, regular treatment with corticosteroids by mouth or by inhalation or both controlled their airflow obstruction. Essential preconditions for inclusion in either group were that the lowest recorded forced expiratory volume in one second $\left(\mathrm{FEV}_{1}\right)$ had to be less than $60 \%$ of the predicted normal value, and that there had to be a record of an increase in $\mathrm{FEV}_{1}$ of at least $30 \%$ after use of a bronchodilator aerosol.

A patient was considered to have corticosteroid-resistant chronic asthma when there was no record of the $\mathrm{FEV}_{1}$ ever having increased by more than $15 \%$ after a seven-day course of at least $20 \mathrm{mg}$ prednisolone daily by mouth. Corticosteroid-responsive patients were selected on the single criterion that their $F_{E V} V_{1}$ had at least once increased by $30 \%$ or more during or at the end of a seven-day course of oral prednisolone $20 \mathrm{mg}$ or more daily. Patients whose increase in $\mathrm{FEV}_{1}$ was between $15 \%$ and $30 \%$ were excluded from the study. All corticosteroid-responsive patients were receiving some form of corticosteroid treatment (prednisolone by mouth, a corticosteroid 
aerosol, or a combination of the two) when they were investigated. Some corticosteroid-resistant patients were still receiving a corticosteroid preparation by mouth or by inhalation, while others were not.

Nine patients with chronic asthma who had not been given corticosteroids served as controls for the laboratory investigations. These patients were given a seven-day course of prednisolone by mouth followed by a corticosteroid aerosol for 14 days. The laboratory investigations were carried out before and at the end of each treatment period in order to observe the short-term effects of the two preparations.

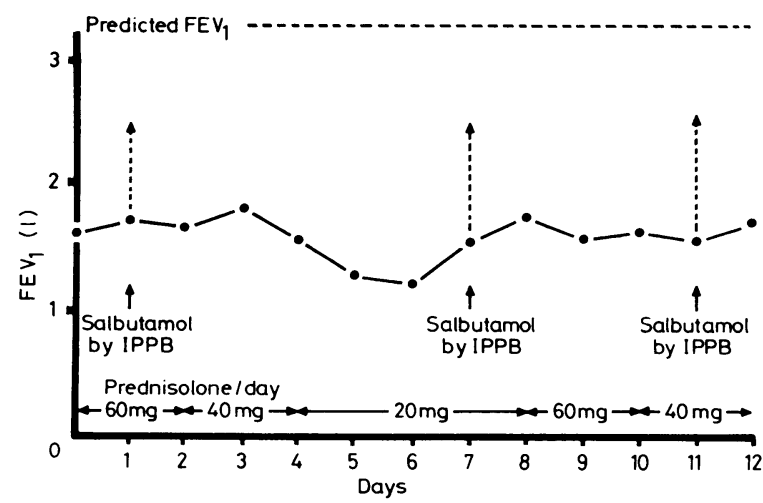

FIG 1-Daily recordings of forced expiratory volume in one second $\left(\mathrm{FEV}_{1}\right)$ in patient with corticosteroid-resistant chronic asthma showing no response to oral prednisolone but good response to salbutamol aerosol administered by intermittent positive-pressure breathing (IPPB)

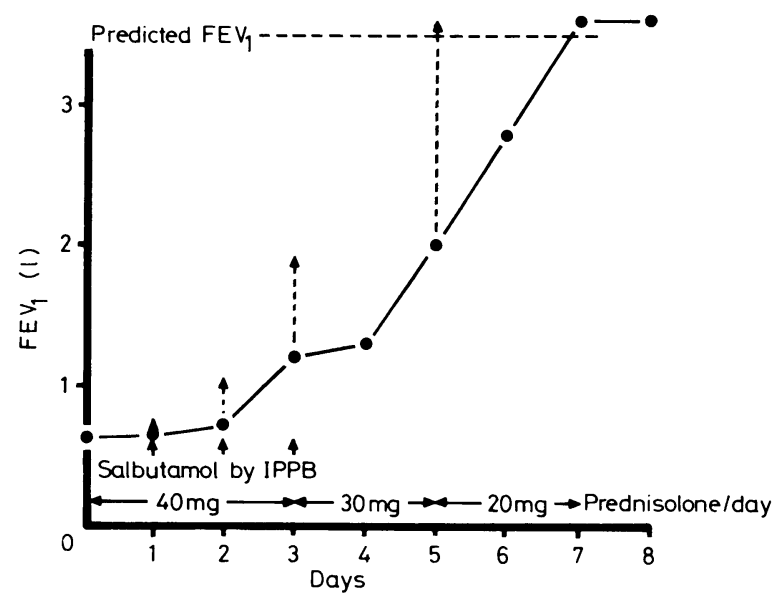

FIG 2-Daily recordings of forced expiratory volume in one second $\left(\mathrm{FEV}_{1}\right)$ in patient with corticosteroid-responsive chronic asthma showing good response to oral prednisolone and initially poor but later good response to salbutamol aerosol administered by intermittent positive-pressure breathing (IPPB).

The final classification of patients in the main study and the numbers in each group and subgroup are given below.

Group 1: corticosteroid-resistant chronic asthma-The 58 patients in this group comprised (a) 20 who were still receiving regular treatment with a combination of prednisolone by mouth and beclomethasone dipropionate aerosol by inhalation; $(b) 20$ who were receiving regular treatment with beclomethasone dipropionate aerosol; and $(c) 18$ who were not receiving regular treatment with any form of corticosteroid.

Group 2: corticosteroid-responsive chronic asthma-All 58 patients in this group were receiving regular treatment with prednisolone by mouth or beclomethasone dipropionate aerosol, or both, when they were studied.

Figures 1 and 2 show typical examples of corticosteroid-resistant and corticosteroid-responsive chronic asthma in terms of changes in $\mathrm{FEV}_{1}$ during the administration of prednisolone by mouth and after $5 \mathrm{mg}$ salbutamol in the form of an aerosol delivered by intermittent positive-pressure breathing. ${ }^{1}$

\section{Methods}

Age, sex, smoking habits, duration of symptoms, family history of asthma, and atopic state of all 116 patients in groups 1 and 2 were recorded. A patient was regarded as atopic if a weal of at least $3 \mathrm{~mm}$ diameter was produced by prick tests with extracts of two or more $C$ allergens, including grass pollen, house dust, Dermatophagoides $\widehat{\widehat{\Omega}}$ pteronyssinus, Aspergillus fumigatus, dog hair, cat fur, and feathers.

In all patients we documented the predicted normal $\mathrm{FEV}_{1}$ and $D$ the greatest response in $\mathrm{FEV}_{1}$ ever recorded to a short course of oral $\mathbb{D}$ prednisolone and to the administration of a salbutamol aerosol by $m$ intermittent positive-pressure breathing. In 47 patients selected at 으 random (33 from group 1, 14 from group 2) the peak expiratory flow rate (PEFR) was measured at four-hour intervals from 0800 until $\vec{\oplus}$ 2000 over seven days. These measurements were made by the $\overline{0}$ patients themselves, who were also asked to record the frequency of nocturnal and early-morning wheeze during the period of observation.

A methacholine challenge test ${ }^{2}$ was carried out on 20 patients selected at random (10 from group 1, 10 from group 2). undertaken on all patients in groups 1 and 2:(a) total white cell and eosinophil counts in the peripheral blood, (b) measurements of immunoglobulins and the fourth component of complement (C4), and $(c)$ studies of monocyte complement receptors and neutrophil superoxide radical production.

The nine previously untreated controls had the same investigations carried out on three separate occasions: $(a)$ before treatment, $(b)$ after N a seven-day course of prednisolone by mouth in a dose of $20 \mathrm{mg}$ daily, and (c) after a 14-day period of treatment with beclomethasone dipropionate aerosol in a dose of $400 \mu \mathrm{g}$ daily.

\section{Results}

Clinical observations-There was no significant difference between the corticosteroid-resistant and corticosteroid-responsive patients in age, sex, smoking habits, and atopic state. Nevertheless, a family history of asthma was more common $(\mathrm{p}<0.001)$ in the corticosteroidresistant asthmatics, and more of these patients $(p<0.01)$ had had symptoms of asthma for over five years when they entered the study (table I).

Effects on airflow obstruction of salbutamol aerosol and of short course of oral preanisolone-After salbutamol the mean $\mathrm{FEV}_{1}$ increased by $61 \%$ in the corticosteroid-resistant patients and by $49 \%$ in the corticosteroid-responsive patients, but this difference was not $\overline{\bar{O}}$ statistically significant. After prednisolone there were increases of $9 \%$ in corticosteroid-resistant patients and $95 \%$ in corticosteroidresponsive patients, this difference being highly significant $(p<0.001)$ (table II).

TABLE I-Comparison of clinical findings in patients with corticosteroid-resistant and corticosteroid-responsive chronic asthma

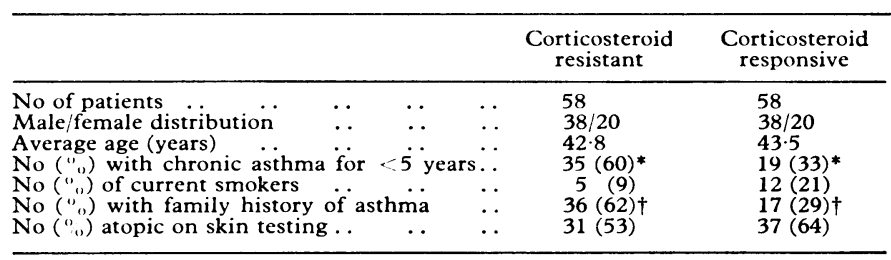

$* \mathrm{p}<0.01$

$+\mathrm{p}<0.001$.

TABLE II-Reversibility studies in patients with corticosteroid-resistant and corticosteroid-responsive chronic asthma (means expressed $\pm S E M$ )

\begin{tabular}{|c|c|c|c|}
\hline & $\begin{array}{c}\text { Corticosteroid } \\
\text { resistant }\end{array}$ & $\begin{array}{l}\text { Corticosteroid } \\
\text { responsive }\end{array}$ & $\begin{array}{c}\mathrm{p} \\
\text { value }\end{array}$ \\
\hline $\begin{array}{llll}\text { No of patients } & \ldots & \ldots & \ldots \\
\text { Mean predicted } F E V_{1}(1) & \ldots & \ldots & \ldots \\
\text { Mean pretreatment } \mathrm{FEV}_{1} \ldots & \ldots & \ldots \\
\text { Mean increase in } \mathrm{FEV}_{1} \text { after salbutamol... } \\
\text { Mean increase in } \mathrm{FEV}_{1} \text { after prednisolone }\end{array}$ & 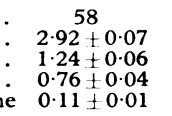 & $\begin{array}{l}38 \\
3 \cdot 0 \pm 0 \cdot 1 \\
1 \cdot 34 \pm 0.07 \\
0 \cdot 64 \pm 0.07 \\
1 \cdot 27 \pm 0.08\end{array}$ & $\begin{array}{c}\text { NS } \\
\text { NS } \\
\text { NS } \\
<0.001\end{array}$ \\
\hline
\end{tabular}

$\mathrm{FEV}_{1}=$ Forced expiratory volume in one second

.

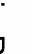

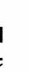
(1) 
TABLE III-Nocturnal or early-morning wheeze or both, and mean morning fall in peak expiratory flow rate (PEFR) in patients with chronic asthma

\begin{tabular}{|c|c|c|c|c|c|c|}
\hline & \multicolumn{3}{|c|}{ Corticosteroid-resistant patients } & \multicolumn{3}{|c|}{ Corticosteroid-responsive patients } \\
\hline & $\begin{array}{c}\text { Nocturnal } \\
\text { wheeze } \\
\text { present }\end{array}$ & $\begin{array}{l}\text { Nocturnal } \\
\text { wheeze } \\
\text { absent }\end{array}$ & $\underset{\text { patients }}{\text { All }}$ & $\begin{array}{l}\text { Nocturnal } \\
\text { wheeze } \\
\text { present }\end{array}$ & $\begin{array}{l}\text { Nocturnal } \\
\text { wheeze } \\
\text { absent }\end{array}$ & $\underset{\text { patients }}{\text { All }}$ \\
\hline 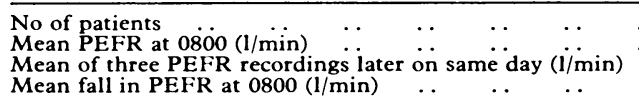 & $\begin{array}{lc} & 14^{*} \\
\cdots & 145 \cdot 7 \\
\cdots & 212 \cdot 1 \\
\cdots & 67 \cdot 4(31 \cdot 8 \%) \S\end{array}$ & $\begin{array}{c}19 \\
263 \cdot 8 \\
300 \cdot 5 \\
36 \cdot 7(12 \cdot 2 \%) \S\end{array}$ & $\begin{array}{c}33 \\
214 \cdot 9 \dagger \\
263 \cdot 0 \pm \\
48 \cdot 1(18 \cdot 3 \%)\end{array}$ & $\begin{array}{c}1 * \\
332 \cdot 0 \\
475 \cdot 0 \\
143 \cdot 0(30 \cdot 1 \%)\end{array}$ & $\begin{array}{c}13 \\
326 \cdot 0 \\
359 \cdot 9 \\
33 \cdot 9(9 \cdot 4 \%)\end{array}$ & $\begin{array}{c}14 \\
326 \cdot 5 \dagger \\
368 \cdot 0 \ddagger \\
41 \cdot 5(11 \cdot 3 \%)\end{array}$ \\
\hline
\end{tabular}

${ }^{*} \mathrm{p}<0.02 . \quad+\mathrm{p}<0.001 . \quad \ddagger \mathrm{p}<0.001 . \quad \$ \mathrm{p}<0.001$

Diurnal variations in severity of asthma-The frequency of nocturnal or early-morning wheeze was compared in 33 patients with corticosteroid-resistant chronic asthma from group 1 and 14 with corticosteroid-responsive chronic asthma from group 2 (table III). Fourteen of the 33 resistant patients but only one of the responsive patients reported regular nocturnal or early-morning wheeze. A $\chi^{2}$ test on a fourfold table showed this difference to be statistically significant $(p<0.02)$. The mean PEFR at 0800 was lower than the mean of the three figures recorded later in the day, both in the corticosteroidresistant and in the corticosteroid-responsive patients. Although this difference was slightly greater in the resistant patients, it was not statistically significant. Further analysis of the data in table III by unpaired $t$ tests, however, showed that the mean PEFR recorded both at 0800 and later in the day was substantially lower in the corticosteroid-resistant patients than in the corticosteroid-responsive patients $(p<0.001)$; also the resistant patients who experienced nocturnal or early-morning wheeze had a much larger fall in mean PEFR at 0800 than those who did not $(\mathrm{p}<0.001)$.

Bronchial reactivity to methacholine-The tests were carried out by the method of Chai et al, ${ }^{2}$ with increasing doses of methacholine beginning with a $0.025 \%$ solution. The procedure was discontinued when the $\mathrm{FEV}_{1}$ fell by more than $20 \%$. Twenty patients were investigated, 10 from the corticosteroid-resistant group and 10 from the corticosteroid-responsive group. As shown in fig 3, bronchial reactivity was significantly greater in the resistant group $(p<0.001)$.
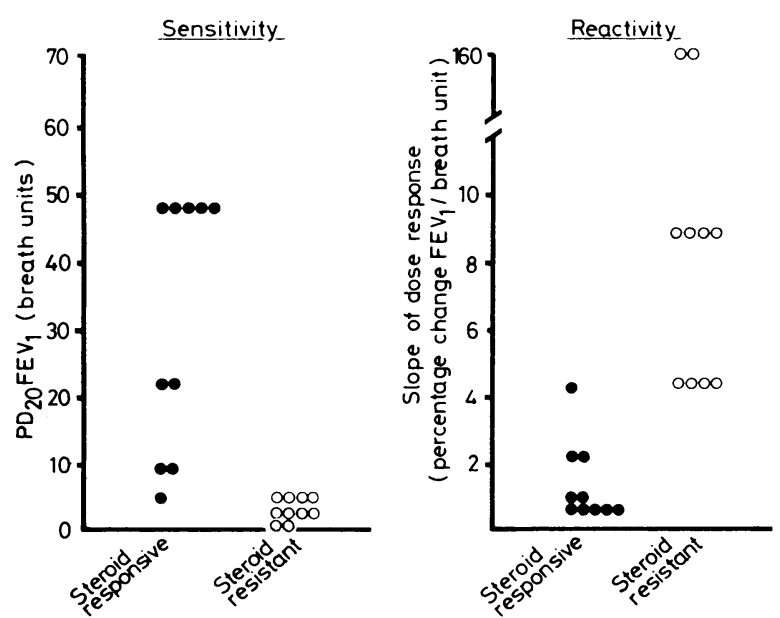

FIG 3-Results of methacholine challenge tests in patients with corticosteroidresponsive and corticosteroid-resistant chronic asthma. One breath unit is equivalent to one inhalation of $1 \%$ methacholine. $\mathbf{P D}_{20}$ is cumulative number of breath units of methacholine which produces $20 \%$ reduction in forced expiratory volume in one second $\left(\mathrm{FEV}_{1}\right)$.

The mean prechallenge $\mathrm{FEV}_{1}$ was lower, however, and there was a greater variation in the severity of airflow obstruction in this group.

Laboratory investigations-No significant differences were observed between corticosteroid-resistant and corticosteroid-responsive chronic asthmatics in total white cell and eosinophil counts in the peripheral blood, measurements of immunoglobulins and C4, and studies of neutrophil superoxide radical production. Nevertheless, in corticosteroid-responsive asthmatics there were lower percentages of monocytes forming rosettes with complement-coated red cells both before and after in-vitro enhancement with casein than in cortico- steroid-resistant asthmatics, and these differences were all statistically significant ( $p<0.025$ or less). That the prednisolone itself might have accounted for these differences was considered unlikely, since the figures both for monocyte complement receptors and for complement receptor enhancement were significantly lower in corticosteroidresponsive patients taking prednisolone than in those corticosteroidresistent patients who were still taking that drug $(p<0.005)$. It was indeed shown in the nine previously untreated chronic asthmatics that the administration of this drug was followed by significant reductions in monocyte complement receptors and complement receptor enhancement $(\mathrm{p}<0.025$ or less), which returned to pretreatment values after the drug was withdrawn. The results of these studies are fully reported elsewhere. ${ }^{3}$

\section{Discussion}

We might have expected that a group of patients with chronic asthma who exhibited no response to systemic treatment with corticosteroids in substantial dosage would have differed in several obvious respects from a group in whom the same form of treatment rapidly and completely relieved their airflow obstruction. In this study, however, the only differences in clinical characteristics between the two groups were that in the corticosteroid-resistant asthmatics a family history of asthma was more common and the duration of asthma before entry to the study was longer. The first difference, which was highly significant $(p<0.001)$, suggested that corticosteroid resistance might have a genetic basis, and HLA studies are now being undertaken to test this. The second difference was less convincing $(p<0.01)$ and may merely have reflected bias in the selection of cases. Patients who have responded well to corticosteroids are apt to be lost from observation, and the 58 patients in this group may thus have belonged to a later generation of patients, with a shorter history of asthma than those with corticosteroid resistance, which may itself contribute to the chronicity of the illness.

Although nocturnal or early-morning wheeze ("morning dipping") 4 was more common in corticosteroid-resistant than in corticosteroid-responsive chronic asthmatics, there was no indication that this clinical phenomenon was in general an intrinsic manifestation of corticosteroid resistance. Indeed, our observations showed that a similar morning fall in mean PEFR occurred in both corticosteroid-resistant and corticosteroidresponsive patients. This suggests that the main reason why it was associated with nocturnal or early-morning wheeze in the resistant patients may have been that they had a more severe degree of airflow resistance, as indicated by the lower mean mean PEFR they recorded at other times of the day $(2631 / \mathrm{min})$, than the responsive patients $(368 \mathrm{l} / \mathrm{min})$. On that basis it could be postulated that the same morning fall in PEFR which produced disturbing symptoms in corticosteroid-resistant patients was insufficient to do so in responsive patients. When, however, the data for the corticosteroid-resistant group are analysed separately it can be seen that much greater absolute and percentage falls in PEFR at 0800 were recorded in those patients who experienced nocturnal or early-morning wheeze than in those who did not. Hence some corticosteroid-resistant patients apparently genuinely differ from responsive asthmatics in that their PEFR tends to fall much more steeply in the 
morning and they are thus more liable to experience nocturnal or early-morning wheeze.

The demonstrably more pronounced degree of bronchial reactivity to methacholine may indicate that one of the effects of corticosteroid resistance is to deprive patients of the protection against this form of bronchial provocation which corticosteroids may provide. The validity of this hypothesis is, however, suspect because prechallenge variations in airflow resistance were greater in the corticosteroid-resistant patients. Hence a pronounced degree of bronchial reactivity cannot be confidently accepted as a specific manifestation of corticosteroid resistance.

All but one of the laboratory investigations failed to identify any characteristic features by which corticosteroid-resistant asthmatics could be recognised. The exception was the study of monocyte complement receptors and their enhancement by casein. This study ${ }^{3}$ suggested that in corticosteroid-resistant asthmatics the administration of prednisolone by mouth does not reduce the number of monocyte complement receptors as it does in corticosteroid-responsive patients. That may explain why bronchial inflammatory reactions affecting monocytes, which may be important in the pathogenesis of bronchoconstriction, are not suppressed by corticosteroids. This concept, if valid, raises the question whether, in seeking an explanation of the phenomenon of corticosteroid resistance in chronic asthma, it would be more profitable to study the biological effects of corticosteroids on monocytes and other cells concerned in all types of immunological response than to concentrate attention on what are, perhaps in most cases, non-specific differences in patterns of bronchial lability and reactivity.

Recognising corticosteroid-resistant chronic asthma is clearly important in clinical practice, if only to ensure that as many patients as possible in this category are spared the potentially $\stackrel{\odot}{\complement}$ serious hazards of continuing a form of treatment from which they are deriving no benefit.

We are grateful to Mrs Honora Knight and Miss June Kidby for technical help and to Miss Allison Gillespie for typing the manuscript. The study was supported by a generous grant from Glaxo Research Limited.

\section{References}

${ }^{1}$ Choo-Kang YFT, Parker SS, Grant IWB. Response of asthmatics to isoprenaline and salbutamol aerosols administered by intermittent positive-pressure ventilation. $\mathrm{Br} \mathrm{Med} \mathcal{F} 1970$;iv:465-8.

2 Chai H, Farr RS, Frochlich LA, et al. Standardisation of bronchial inhalation challenge procedures. $f$ Allergy Clin Immunol 1975;56: 323-7.

3 Kay AB, Diaz P, Carmichael J, Grant IWB. Corticosteroid-resistant $\vec{\omega}$ chronic asthma and monocyte complement receptors. Clin Exp Immunol (in press).

4 Turner-Warwick $M$. On observing patterns of airflow obstruction in chronic asthma. $\mathrm{Br} \mathcal{F}$ Dis Chest $1977 ; 71: 73-86$.

(Accepted 10 March 1981)
ONE HUNDRED YEARS AGO SIR,-Hitherto, though I have thought much, I have written nothing, regarding the imbroglio at Guy's hospital. But the letter of "A Metropolitan Hospital Surgeon," in your issue of December 25th, induces, or rather compels, me to abandon my expectant attitude, and endeavour briefly to set before your readers a view of the present state of matters, somewhat more in accordance with the fact than the effusion of your anonymous surgical correspondent.

Let me premise that the strife, in the previously peaceful and prosperous hospital, was commenced by the arbitrary proceedings of the new treasurer and the newer matron, both of whom seemed determined to magnify their office at the expense of the hospital, the nurses, the patients, and the medical staff. These last, being frequently subjected to inconvenience and annoyance in the discharge of their duties, and finding the nursing arrangements of the wards overturned at the caprice of the matron, and, as everybody knows, to the detriment of the patients-in order, as some of the staff believed, to carry out an ecclesiastical system which provokes much more to ill will and confusion, than to love and good works-opposed for a considerable period, a united and unbroken resistance to the new officials and their measures; and, in particular, demanded the removal of the matron. An unfortunate sentence, which was capable of being construed in an offensive sense, led the governors to request the resignation of $\mathrm{Dr}$ Habershon and $\mathrm{Mr}$ Cooper Forster, who, as senior physician and surgeon, had signed the memorial of August 13th to the governors, on behalf of the medical staff. With the withdrawal of this memorial, and the concession by the governors of the right of two members of the staff to attend "the taking-in committee," the unanimity of the staff seems to have ceased; and the views, once so resolutely upheld by every member of it, seem now to be maintained only by Dr Habershon and $\mathrm{Mr}$ Cooper Forster.

On October 14th, the governors, while not insisting on the resignation of these two gentlemen, go on to say: "The governors, however, must at the same time record their resolution to maintain in its integrity the power to govern the hospital, entrusted to them by law, and this resolution must be accepted by the medical staff." The decision of the two seniors was at once taken. They saw that matters were substantially unchanged; that nothing of all they had been contending for had been granted, except the right to attend the subcommittee, to the constitution of which many of the staff strongly objected; and this equivocal boon was accompanied by an assertion of irresponsible power over the medical staff, so vulgar and offensive, that Dr Habershon and Mr Cooper Forster at once wrote their letters of resignation. This instinctive protest against insult and tyranny would have been carried out without delay, and without counting the cost, but for the earnest request of their colleagues, that they should remain. $N$ They consented to do so till they had finished their clinical lectures. This done, they at once gave effect to their resolution, which they had never abandoned, and severed the connection which had been so honourable $\vec{\varphi}$ to them, and so beneficial to the hospital and its school; not without $\infty$ much pain, but with a clear conscience.

And now, our anonymous surgeon seeks to minimise this act of selfsacrifice, by representing it as merely the anticipation, by "a month or two" of their necessary retirement. The truth is, that Dr Habershon had five, and $\mathrm{Mr}$ Cooper Forster, three years to run of their natural term of office. If we suppose the yearly emoluments to be $£ 350$, and I should think they cannot be less, their resignations imply the pecuniary sacrifice in the one case of $£ 1,750$, and in the other, of $£ 1,050$, besides the much greater one of abruptly terminating their hospital labours, in the full vigour of their powers, and ripeness of their professional experience. What could prompt this, but the firm conviction of the impropriety of continuing to hold office on such terms as were prescribed by the governors? I do not judge those who have felt it their duty to remain; but I protest against this ungenerous attempt to depreciate the motives and conduct of the seceders, whose names will long be held in honoured and affectionate remembrance by the multitude of men who have gone forth from Guy's during the last forty years to practise their profession in every quarter of the globe. Yours faithfully, A P STEWART. (British Medical fournal, 1881.)

ONE HUNDRED YEARS AGO Dr Rees Philipps, of the Wonford Hospital for the Insane at Exeter, expresses in his annual report his grateful acknowledgments to Mr James D Doulton for a large and valuable contribution of specimens of Doulton ware and $N$ Lambeth faïence for the decoration of the wards. No doubt beauty and $\omega$ harmony of form and colour must have a tranquillising effect even on the "mind diseased"; and, if lunatics can be got to "live up to" $O$ Doulton ware, to say nothing of blue china, an important step will $\Phi$ have been gained in moral treatment. The invariable experience of the $\stackrel{\leftrightarrow}{+}$ Commissioners in Lunacy has been, that decoration and destruction in 7 lunatic asylums are in the inverse ratio of each other; and that shapely furniture, mirrors, pictures, and ornaments may be introduced safely into refractory wards, which cease to be refractory when they attain a certain stage of artistic finish; such things being respected and left intact, when deal tables and tin cans are ruthlessly knocked about. The Kyrle Society may yet bring lunatic asylums within the scope of its beneficent efforts, and supply an element of moralising refinement that is now often wanting in the well-meant attempts at decoration met with in these establishments. (British Medical fournal, 1881.) 